\title{
Lung Recruitment Maneuvers Using Direct Ultrasound Guidance: A Case Study
}

\author{
Jiang Du MD, Jiuting Tan MD, Kanglong Yu MD, and Ruilan Wang MD
}

\begin{abstract}
Previous studies have shown that lung recruitment maneuvers are important means of treating ARDS. Although computed tomography (CT) scans and pressure-volume curves are the most common ways to evaluate lung recruitment, there are still many disadvantages. Not only do the scans have to take place in a CT room, but the patient is exposed to large doses of radiation through the multiple scans necessary to define the optimal PEEP. Pressure-volume curves require deep sedation and muscle relaxation. Thus, bedside lung ultrasound may be considered to be a safer and easier alternative to $\mathrm{CT}$ scans or pressure-volume curves. In our case, we evaluated the effectiveness of lung recruitment with a bedside ultrasound on a patient who was suffering from life-threatening hypoxemia. Bedside ultrasound is a faster and more convenient imaging method because it reduces the need for patient transport compared with CT scan and requires no muscle relaxation. This case supports that ultrasound may become an alternative imaging tool to guide and evaluate alveolar recruitment in patients with ARDS. Additionally, we have also included a brief review of lung recruitment evaluation by ultrasound to supplement this case study. Key words: ultrasound; ARDS; lung recruitment;. [Respir Care 2015;60(5):e93-e96. () 2015 Daedalus Enterprises]
\end{abstract}

\section{Introduction}

Lung recruitment maneuvers are important in the treatment of ARDS. Although their effect on final mortality is still under debate, recruitment maneuvers can improve oxygenation for patients who are suffering from life-threating hypoxemia. There are many methods used to evaluate the effectiveness of recruitment, including computed tomography $(\mathrm{CT})$ scans and pressure-volume (P-V) curves. However, the disadvantages of a CT scan include the need to transport the patient to the $\mathrm{CT}$ room and the

The authors are affiliated with Department of Critical Care Medicine, Shanghai First People's Hospital, Shanghai Jiao Tong University, Shanghai, China.

The authors have disclosed no conflicts of interest.

The first 2 authors contributed equally to this work.

Correspondence: Ruilan Wang MD, Department of Critical Care Medicine, Shanghai First People's Hospital, Shanghai Jiao Tong University, Shanghai 200240, China. E-mail: wangyusun@ hotmail.com.

DOI: $10.4187 /$ respcare.03056 increased radiation exposure to define optimal PEEP with multiple scans. The disadvantages of $\mathrm{P}-\mathrm{V}$ curves are the requirements for deep sedation and muscle relaxation. As a result, lung ultrasound is a safer and more convenient alternative to $\mathrm{CT}$ scans or P-V curves.

\section{Case Report}

A 72-y-old male was admitted to the hospital on April 16,2013 , with a chief complaint of cough and fever for $3 \mathrm{~d}$. His chest CT on the first day of admission showed pneumonia in the right lung. On the second day of admission, the patient deteriorated rapidly with high fever, severe hypoxia, and tachypnea. The arterial blood gas showed a $\mathrm{P}_{\mathrm{aO}_{2}}$ of $52 \mathrm{~mm} \mathrm{Hg}$ despite an oxygen flow of $>10$ $\mathrm{L} / \mathrm{min}$. Bedside ultrasonography was performed and revealed significant pulmonary consolidation and a dynamic bronchus sign in the right lung. Intubation and ventilation were initiated immediately. A repeat CT scan of the chest showed rapidly progressing pneumonia and a large area of consolidation (Fig. 1) in the right lung. These findings were consistent with the results of the ultrasound (Fig. 2).

The patient continued to deteriorate and soon developed tachycardia, hypotension, and anuria. Fluid resuscitation 


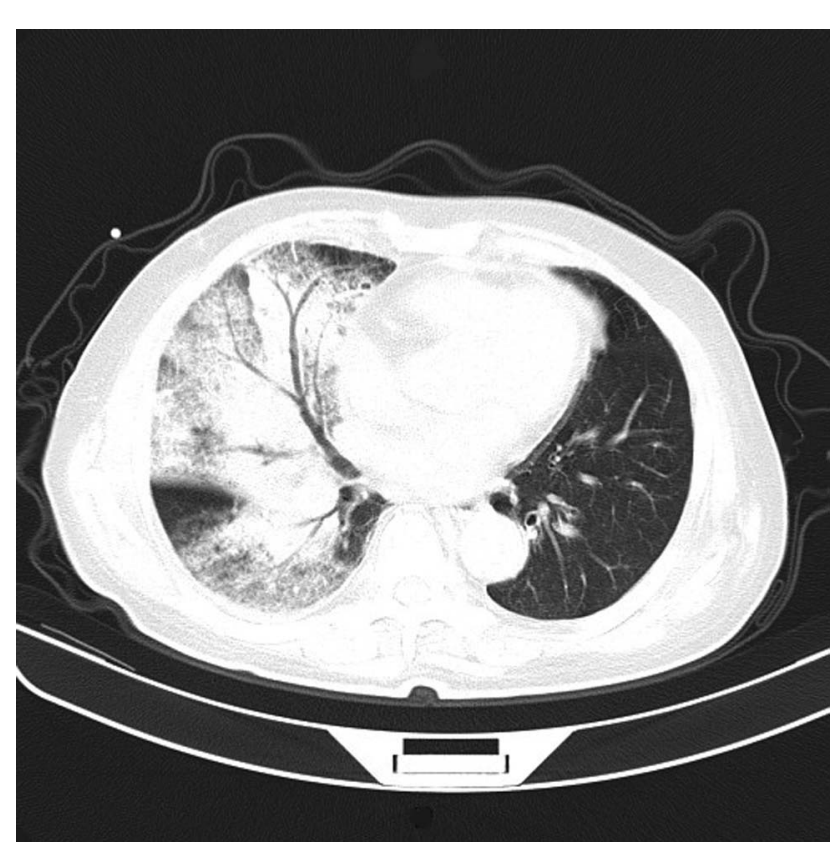

Fig. 1. Chest computed tomography $2 \mathrm{~d}$ after admission.

and continuous renal replacement therapy were started along with hemodynamic monitoring. The arterial blood gas on April 17, 2013, showed a $\mathrm{P}_{\mathrm{aO}_{2}}$ of $69 \mathrm{~mm} \mathrm{Hg}$ and $\mathrm{P}_{\mathrm{aO}_{2}} / \mathrm{F}_{\mathrm{IO}_{2}}$ of $76 \mathrm{~mm} \mathrm{Hg}$ with an $\mathrm{F}_{\mathrm{IO}_{2}}$ under 0.90 .

At this point, the PEEP was adjusted to $15 \mathrm{~cm} \mathrm{H}_{2} \mathrm{O}$, but the arterial blood gas showed little improvement. The $\mathrm{F}_{\mathrm{IO}_{2}}$ still needed to be maintained at 0.75 and could not be lowered to 0.60 . The diagnoses of severe pneumonia and ARDS were confirmed, and lung recruitment maneuvers were performed. A PEEP of $40 \mathrm{~cm} \mathrm{H}_{2} \mathrm{O}$ was applied during the recruitment maneuver, and the PEEP was set at $20 \mathrm{~cm} \mathrm{H}_{2} \mathrm{O}$ thereafter. Ultrasound with a $1-5-\mathrm{MHz}$ probe (M-Turbo, SonoSite, Shanghai, China) was used to guide the maneuvers and monitor the lung status. The PEEP was gradually increased. Our objective with PEEP was to obtain an $\mathrm{S}_{\mathrm{pO}_{2}}$ of $>95 \%$ with an $\mathrm{F}_{\mathrm{IO}_{2}}$ of $<0.60$. The inspiratory pressure was adjusted to $10 \mathrm{~cm} \mathrm{H}_{2} \mathrm{O}$ above PEEP, at which the tidal volume was nearly $400 \mathrm{~mL}(6 \mathrm{~mL} / \mathrm{kg}$ for this $70-\mathrm{kg}$ patient with a tolerable $\mathrm{pH}$ of $>7.20$ ) with an upper limit of $50 \mathrm{~cm} \mathrm{H}_{2} \mathrm{O}$ using a $\mathrm{PB} 840$ ventilator (Puritan Bennett, Pleasanton, California). The probe was placed at the right side of the chest wall near the posterior axillary line, between the fourth and fifth ribs. The ultrasound image is shown in Figure 3A. When the PEEP was initially increased from 5 to $20 \mathrm{~cm} \mathrm{H}_{2} \mathrm{O}$ for $10 \mathrm{~s}$, the area of consolidation was significantly decreased (Fig. 3B). When the PEEP was further increased to $30 \mathrm{~cm} \mathrm{H}_{2} \mathrm{O}$ for $10 \mathrm{~s}$, the area of consolidation decreased again accordingly (Fig. 3C). Finally, when the PEEP reached $40 \mathrm{~cm} \mathrm{H}_{2} \mathrm{O}$ and was maintained for $\sim 40 \mathrm{~s}$, most of the consolidation was

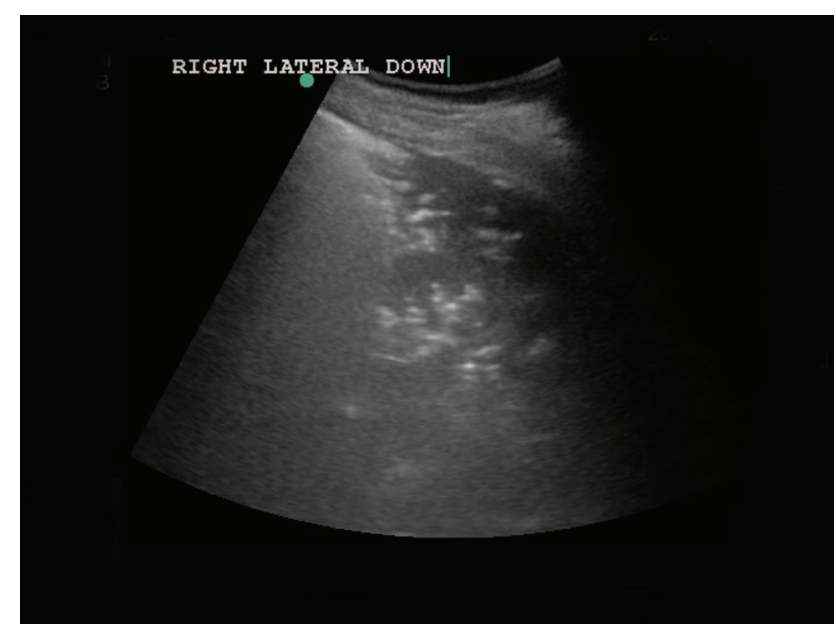

Fig. 2. Lung consolidation using ultrasound.

replaced by recruited lung tissue (Fig. 3D). Subsequently, the PEEP was decreased and maintained at $20 \mathrm{~cm} \mathrm{H}_{2} \mathrm{O}$.

Arterial blood gases were taken at this time and showed a $\mathrm{P}_{\mathrm{aO}_{2}}$ of $100 \mathrm{~mm} \mathrm{Hg}$ and $\mathrm{P}_{\mathrm{aO}_{2}} / \mathrm{F}_{\mathrm{IO}_{2}}$ of $167 \mathrm{~mm} \mathrm{Hg}$ with an $\mathrm{F}_{\mathrm{IO}_{2}}$ of 0.60 . The oxygenation improved compared with the arterial blood gas before recruitment, at which time the $\mathrm{P}_{\mathrm{aO}_{2}}$ was $89 \mathrm{~mm} \mathrm{Hg}$, the $\mathrm{F}_{\mathrm{IO}_{2}}$ was 0.75 , and $\mathrm{P}_{\mathrm{aO}_{2}} / \mathrm{F}_{\mathrm{IO}_{2}}$ was $119 \mathrm{~mm} \mathrm{Hg}$. Twelve h later, the arterial blood gas showed that the $\mathrm{P}_{\mathrm{aO}} / \mathrm{F}_{\mathrm{IO}_{2}}$ was $261 \mathrm{~mm} \mathrm{Hg}$. These parameters indicate significant improvement of oxygenation after lung recruitment under direct ultrasound guidance. However, after $24 \mathrm{~h}$ at a PEEP of $20 \mathrm{~cm} \mathrm{H}_{2} \mathrm{O}$, hemodynamic monitoring showed decreased global end-diastolic volume, and the cardiac index decreased from $2.9 \mathrm{~L} / \mathrm{min} / \mathrm{m}^{2}$ to $<2$ $\mathrm{L} / \mathrm{min} / \mathrm{m}^{2}$ due to the patient's poor cardiac function. Because $\mathrm{P}_{\mathrm{aO}_{2}} / \mathrm{F}_{\mathrm{IO}_{2}}$ improved, we gradually lowered the PEEP to $12 \mathrm{~cm} \mathrm{H}_{2} \mathrm{O}$ over the next $48 \mathrm{~h}$ to prevent a pneumothorax. During this period, the cardiac index returned to $>2.5 \mathrm{~L} / \mathrm{min} / \mathrm{m}^{2}$. After $10 \mathrm{~d}$ of continuous renal replacement therapy, antibiotics, antiviral medication, and supportive therapies, the patient's renal function returned to normal. He was extubated $33 \mathrm{~d}$ later and discharged $10 \mathrm{~d}$ after extubation.

\section{Discussion}

ARDS caused by severe pneumonia can lead to severe hypoxia, sepsis, multiple organ dysfunction, and even death. Although lung recruitment maneuvers can improve oxygenation in patients with ARDS, its positive effect on final mortality is still under debate. ${ }^{1}$ Response to PEEP in a heterogeneous population of patients with ARDS is highly variable. Thus, the benefits of recruitment maneuvers and higher levels of PEEP for some might have be harmful to others. ${ }^{2}$ A quick evaluation of lung recruitment ability is necessary. P-V curves and CT scans are the 2 most 

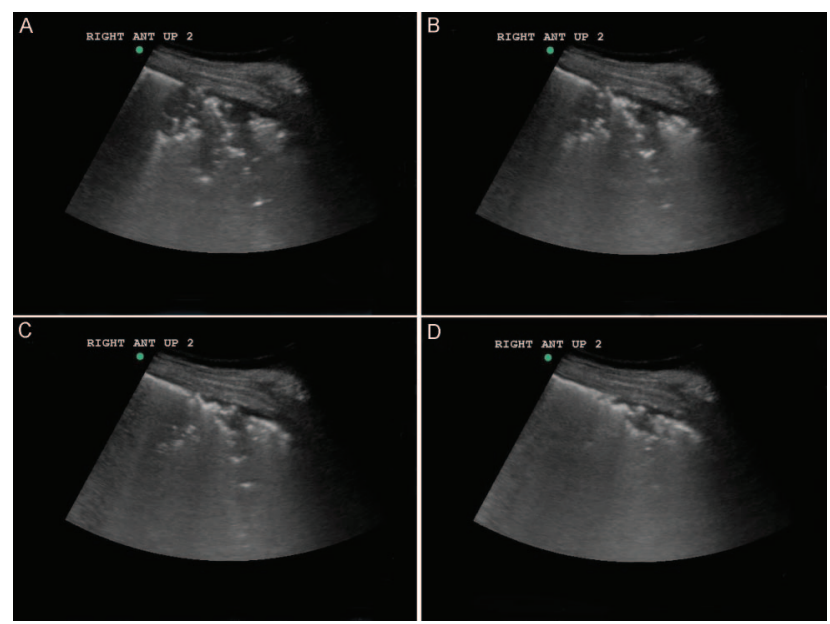

Fig. 3. Pulmonary ultrasound during a recruitment maneuver. A: PEEP $=5 \mathrm{~cm} \mathrm{H}$ O. B: PEEP $=20 \mathrm{~cm} \mathrm{H}_{2} \mathrm{O}$. C: PEEP $=30 \mathrm{~cm} \mathrm{H}_{2} \mathrm{O}$. D: $P E E P=40 \mathrm{~cm} \mathrm{H}_{2} \mathrm{O}$.

commonly used tools to evaluate the effectiveness of recruitment. Other methods include electrical impedance tomography and positron emission tomography. Lung ultrasound is a new way to evaluate lung recruitment maneuvers.

Although ultrasound was not found to be suitable in cases of normal lung physiology, it has been found to be highly accurate in the assessment of pathological lungs. It shows high sensitivity and specificity in diagnosing pneumonia, pneumothorax, and interstitial syndrome. ${ }^{3}$ Ultrasound can determine pneumonia by specific indications such as hepatization and the dynamic bronchus sign. ${ }^{4}$ In this case, the pulmonary ultrasound of the patient showed signs of consolidation consistent with pneumonia. During the maneuver on our patient, we observed that as the PEEP increased, the collapsed alveoli became re-inflated. By using ultrasound, the area of consolidation (see Fig. 1) was gradually replaced by vertical B-lines, which represent re-aerated lung tissue (Fig. 4). The trend of the patient's blood gas change was in accordance with the ultrasound images. The $\mathrm{P}_{\mathrm{aO}_{2}} / \mathrm{F}_{\mathrm{IO}_{2}}$ increased from 119 to $167 \mathrm{~mm} \mathrm{Hg}$ after the maneuver, and improved to $261 \mathrm{~mm} \mathrm{Hg}$ after $12 \mathrm{~h}$.

Two similar cases were reported by Gardelli et $\mathrm{al}^{5}$ and Santuz et al. ${ }^{6}$ Neither demonstrated how to evaluate the re-aeration quantitatively. Quantitative measurement is based on changes in areas of lung consolidation. Stefanidis et $\mathrm{al}^{7}$ performed the lung recruitment maneuver on 10 subjects who presented with lung consolidation. They observed the area of consolidation before $\left(\mathrm{PEEP}=5 \mathrm{~cm} \mathrm{H}_{2} \mathrm{O}\right)$ and after $\left(\mathrm{PEEP}=15 \mathrm{~cm} \mathrm{H}_{2} \mathrm{O}\right)$ the maneuver with ultrasound to evaluate the re-aeration effect of the recruitment. The authors demonstrated a correlation between the ultrasound image and change in blood gas. This supports the practical use of ultrasound to view lung consolidation in

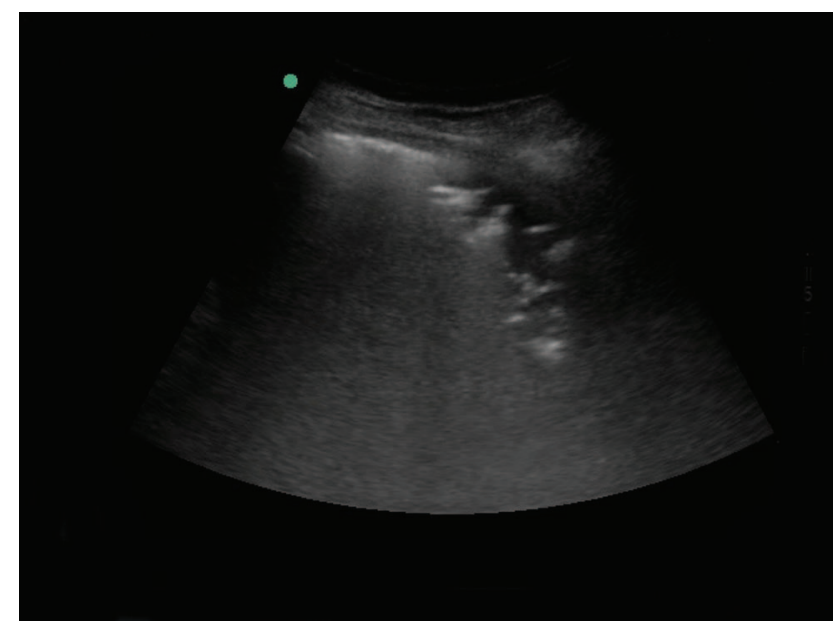

Fig. 4. Consolidation replaced by B-lines after recruitment maneuver.

patients with ARDS and to guide bedside lung recruitment.

Other semiquantitative methods are introduced by ultrasound scores. In patients with pulmonary edema, the ultrasound score is based on the number of vertical B-lines detected in anterior and lateral parts of the chest wall. ${ }^{8,9}$ In patients with ARDS and/or pneumonia, consolidated lung areas coexist with interstitial and alveolar edema. Therefore, another semiquantitative scoring method was introduced by Bouhemad et al. ${ }^{10,11}$ They characterized the ultrasound findings in pneumonia into 4 levels: consolidation (complete loss of aeration), coalescent B-lines (severe loss of aeration), multiple B-lines (moderate loss of aeration), and normally inflated lung tissue. They numbered the change on ultrasound before and after the recruitment maneuver by re-aeration score: 1 point, from multiple B-lines to normal, from coalescent B-lines to multiple B-lines, and from consolidation to coalescent B-lines; 3 points, from coalescent B-lines to normal or from consolidation to multiple B-lines; and 5 points, from consolidation to normal. The mean lung ultrasound score of re-aeration was then calculated for the 12 regions examined, including the upper and lower parts of the anterior, lateral, and posterior right and left chest walls. The conclusion reached by Bouhemad et al. ${ }^{10,11}$ was that the effectiveness of recruitment can be evaluated directly by ultrasound.

A CT scan enables us to evaluate the recruited lung field quantitatively by measuring the CT values. The lung regions can be classified as non-aerated, poorly aerated, normally aerated, and hyperinflated by $\mathrm{CT}$ values. The percentage of potentially recruitable lung can also be measured by the proportion of the total lung weight accounted for by non-aerated lung tissue to which aeration was restored (according to CT). ${ }^{12}$ However, the disadvantages of a CT scan are obvious: not only must the procedure take place in a CT room, but it exposes the patient to large doses of 


\section{LUNG RECRUITMENT USING UltRASOUND}

radiation through the multiple scans necessary to define the optimal PEEP. The studies of re-aeration score by Bouhemad et al. ${ }^{11}$ have shown that resolution of ventilator-associated pneumonia with antimicrobial therapy can be accurately assessed by ultrasound: a tight and significant correlation was found between an increase in CT lung aeration after antibiotic administration and an ultrasound re-aeration score based on observed changes in ultrasound patterns. Therefore, it is reasonable to hypothesize that a change in lung aeration resulting from any therapy (such as recruitment maneuvers) aimed at reversing aeration loss characterizing acute lung injury or ARDS might be detected by corresponding changes in ultrasound patterns. ${ }^{11}$

A P-V curve is another important tool used to evaluate recruitment. ${ }^{13}$ In ARDS patients treated with lung recruitment maneuvers by PEEP, the application of PEEP causes an upward shift in the P-V curve, indicating alveolar recruitment. The recruited lung volume is calculated as the difference in the volumes between zero end-expiratory pressure and PEEP for the same alveolar pressure. However, deep sedation and muscle relaxation are the prerequisites of an accurate P-V curve and cannot be performed in spontaneously breathing patients. Bouhemad et $\mathrm{al}^{10} \mathrm{com}-$ pared P-V curves and ultrasound in a lung re-aeration assessment of 30 subjects with ARDS. PEEP-induced lung recruitment was measured using the $\mathrm{P}-\mathrm{V}$ curve method, ultrasound changes were also measured, and an ultrasound re-aeration score was calculated. A highly significant correlation was found between PEEP-induced lung recruitment measured by $\mathrm{P}-\mathrm{V}$ curves and ultrasound re-aeration score.

Electrical impedance tomography ${ }^{14}$ and positron emission tomography ${ }^{15}$ can also be used to evaluate lung recruitment. These 2 methods are not commonly used. Moreover, we found no literature comparing ultrasound with electrical impedance tomography or positron emission tomography in evaluation of lung recruitment.

Lung ultrasound can be used to evaluate lung recruitment capability and the effectiveness of the therapy for patients with ARDS. However, how to accurately quantify the capability using ultrasound remains unsolved. Additional studies are needed to prove whether lung ultrasound is an effective and feasible tool for the diagnosis and treatment of ARDS. In the future, ultrasound may became the primary means for diagnosis, treatment (lung recruitment), and evaluation of patients with ARDS.

\section{REFERENCES}

1. Fan E, Wilcox ME, Brower RG, Stewart TE, Mehta S, Lapinsky SE, et al. Recruitment maneuvers for acute lung injury: a systematic review. Am J Respir Crit Care Med 2008;178(11):1156-1163.

2. Meade MO, Cook DJ, Guyatt GH, Slutsky AS, Arabi YM, Cooper DJ, et al. Ventilation strategy using low tidal volumes, recruitment maneuvers, and high positive end-expiratory pressure for acute lung injury and acute respiratory distress syndrome: a randomized controlled trial. JAMA 2008;299(6):637-645.

3. Volpicelli G, Elbarbary M, Blaivas M, Lichtenstein DA, Mathis G, Kirkpatrick AW, et al. International evidence-based recommendations for point-of-care lung ultrasound. Intensive Care Med 2012; 38(4):577-591.

4. Lichtenstein DA, Lascols N, Mezière G, Gepner A. Ultrasound diagnosis of alveolar consolidation in the critically ill. Intensive Care Med 2004;30(2):276-281.

5. Gardelli G, Feletti F, Gamberini E, Bonarelli S, Nanni A, Mughetti M. Using sonography to assess lung recruitment in patients with acute respiratory distress syndrome. Emerg Radiol 2009;16(3):219221.

6. Santuz P, Bonetti P, Serra A, Biban P. Ultrasound-guided lung recruitment in a young infant with ARDS. Paediatr Anaesth 2010; 20(9):895-896.

7. Stefanidis K, Dimopoulos S, Tripodaki ES, Vitzilaios K, Politis P, Piperopoulos $\mathrm{P}$, et al. Lung sonography and recruitment in patients with early acute respiratory distress syndrome: a pilot study. Crit Care 2011;15(4):R185.

8. Jambrik Z, Monti S, Coppola V, Agricola E, Mottola G, Miniati M, Picano E. Usefulness of ultrasound lung comets as a nonradiologic sign of extravascular lung water. Am J Cardiol 2004;93(10):12651270.

9. Frassi F, Gargani L, Tesorio P, Raciti M, Mottola G, Picano E. Prognostic value of extravascular lung water assessed with ultrasound lung comets by chest sonography in patients with dyspnea and/or chest pain. J Card Fail 2007;13(10):830-835.

10. Bouhemad B, Brisson H, Le-Guen M, Arbelot C, Lu Q, Rouby JJ. Bedside ultrasound assessment of positive end-expiratory pressureinduced lung recruitment. Am J Respir Crit Care Med 2011;183(3): 341-347.

11. Bouhemad B, Liu ZH, Arbelot C, Zhang M, Ferarri F, Le-Guen M, et al. Ultrasound assessment of antibiotic-induced pulmonary reaeration in ventilator-associated pneumonia. Crit Care Med 2010;38(1): 84-92.

12. Gattinoni L, Caironi P, Cressoni M, Chiumello D, Ranieri VM, Quintel M, et al. Lung recruitment in patients with the acute respiratory distress syndrome. N Engl J Med 2006;354(17):1775-1786.

13. Lu Q, Rouby JJ. Measurement of pressure-volume curves in patients on mechanical ventilation: methods and significance. Crit Care 2000; 4(2):91-100.

14. Lowhagen K, Lundin S, Stenqvist O. Regional intratidal gas distribution in acute lung injury and acute respiratory distress syndromeassessed by electric impedance tomography. Minerva Anestesiol 2010;76(12):1024-1035.

15. Bellani G, Amigoni M, Pesenti A. Positron emission tomography in ARDS: a new look at an old syndrome. Minerva Anestesiol 2011; 77(4):439-447. 